\title{
Thyroid Abnormalities in Relation to Type 1 and Type 2 Diabetes Mellitus Patients in Quetta, Balochistan
}

\author{
Mohsin Ali ${ }^{1}$, Nargis Haider Kakar ${ }^{2}$, Rida Dawood ${ }^{3,4}$, Qurat-ul-ain Fatima, \\ Zunera Tanveer ${ }^{2}$, Shoaib Ahmad Malik ${ }^{6}$, Tauseef Muhammad Asmat ${ }^{1}$, Asadullah ${ }^{1}$, \\ Muhammad Masood Tariq Kiani ${ }^{1}$ and Mohammad Zahid Mustafa ${ }^{1 *}$ \\ ${ }^{1}$ Centre for Advanced Studies in Vaccinology and Biotechnology (CASVAB), University \\ of Balochistan, Quetta, Pakistan \\ ${ }^{2}$ Department of Physiology, Bolan University of Medical and Health Sciences, Quetta, \\ Pakistan \\ ${ }^{3}$ Department of Medical Education, University of Health Sciences, Lahore, Pakistan. \\ ${ }^{4}$ Children Hospital \& Institute of Child Health, Faisalabad, Pakistan \\ ${ }^{5}$ Physiology Department, Pak Red Crescent Medical and Dental College, Dina Nath, \\ Kasur, Pakistan \\ ${ }^{6}$ Department of Biochemistry, Sargodha Medical College, University of Sargodha, \\ Sargodha, Pakistan
}

\begin{abstract}
A B S T R A C T
Diabetes mellitus (DM) is responsible for a large number of deaths worldwide, and diabetic patients are at risk of having other immune diseases including thyroid abnormalities. The current study, undertaken in collaboration with Shaikh Khalifa-Bin-Zayed Hospital Quetta, investigates the relation of thyroid abnormalities in $224 \mathrm{DM}$ (both type 1 and type 2) patients. The parameters of age, duration of diabetes and type of treatment were measured. Venous blood was taken to investigate the thyroid profiles. Out of 224 patients examined, $67.85 \%$ showed the normal thyroid profile and thyroid abnormalities were seen in $32.15 \%$ of subjects. There were 10 patients with clinical hypothyroidism, 54 patients had subclinical hypothyroidism, and 8 patients had clinical hyperthyroidism. No case with subclinical hyperthyroidism was investigated. The female population (58.93\% of the study) had higher risk of developing thyroid abnormality as compared to males. Out of $32.15 \%$ patients with thyroid abnormalities, $67 \%$ were female. Moreover, $41 \%$ of type 1 diabetic patients had thyroid abnormalities as compared to $31 \%$ of type 2 diabetic patients, indicating that type 1 diabetics are more prone to develop thyroid abnormalities. According to our data diabetics are more prone to develop thyroid abnormalities. Regular screening of the thyroid profile is recommended for timely diagnosis of thyroid abnormalities in diabetics to lessen the risk of development associated co-morbidities.
\end{abstract}

\begin{tabular}{|c|}
\hline Article Information \\
\hline Received 12 October 2019 \\
\hline Revised 23 December 2019 \\
\hline Accepted 14 January 2020 \\
\hline Available online 22 February 2021 \\
\hline Authors' Contribution \\
\hline $\begin{array}{l}\text { MA, NHK and ZT designed the } \\
\text { experiments and acquired the data. }\end{array}$ \\
\hline $\begin{array}{l}\text { RD, QF and TMA did statistical } \\
\text { analysis and compiled the results. }\end{array}$ \\
\hline $\begin{array}{l}\text { Asadullah and MMTK helped in } \\
\text { interpretation of the data. SAM }\end{array}$ \\
\hline \\
\hline $\begin{array}{l}\text { and supervised the study. All authors } \\
\text { contributed in manuscript writing. }\end{array}$ \\
\hline Key words \\
\hline $\begin{array}{l}\text { Type } 1 \text { diabetes mellitus, Type } 2 \\
\text { diabetes mellitus, Thyroid disease, } \\
\text { Hypothyroidism, Hyperthyroidism }\end{array}$ \\
\hline
\end{tabular}

\section{INTRODUCTION}

$\mathrm{T}$ hyroid diseases (TD) and diabetes mellitus (DM) are the two most common endocrine related disorders that are encountered in clinical practice (Aggarwal and Rizvi, 2013). DM is a group of metabolic disorders characterized by increased levels of glucose in the blood resulting from impaired metabolism of glucose due to abnormal functioning of insulin either in its secretion or action resulting in a hyperglycemic condition (Wild et al, 2004).

\footnotetext{
* Corresponding author: zunzah@gmail.com; drzahid. casvab@uob.edu.pk 0030-9923/2021/0002-0669 \$ 9.00/0

Copyright 2021 Zoological Society of Pakistan
}

The global prevalence rate of DM is $8.5 \%$ in adults and is an established risk factor for coronary heart disease and stroke (Sarwar et al., 2010). In Pakistan it is estimated that the overall age-adjusted weighted prevalence of diabetes is $26.3 \%$ (Basit et al., 2018). According to a report of the World Health Organization (WHO), there will be an estimated increase in the worldwide prevalence of diabetes from 280 to 300 million by 2030. Obesity, hypertension, nutritional imbalance, and modern lifestyle are major contributors to this epidemic (Zimmat et al, 2001).

TD and DM mutually influence each other and the association between both conditions is well documented (Aggarwal and Rizvi, 2013). Thyroid disorders (both hyperthyroidism and hypothyroidism) are quite common clinically with prevalence rates of around $0.5 \%$ to $2 \%$ 
(Vanderpump, 2011). In 1927 a study revealed the first proven interaction of diabetes with thyroid diseases in the general population (Coller and Huggins, 1927) and after that further research has been done to set up the association connecting both thyroid disease and diabetes (Wang, 2013; Galag et al., 2016; Khurana et al., 2016).

Studies have reported that $6-24 \%$ of patients with type 1 DM (T1DM), and 3-6\% with type 2 DM (T2DM) have hypothyroidism. Female subjects with T1DM are more prevalent to such thyroid abnormalities than those with T2DM. Moreover, hyperthyroidism is found in $1-2 \%$ of patients presenting with diabetes (Guillermo et al., 2003). Due to similar signs and symptoms of both these diseases, either of them remains undiagnosed by the physicians and medical experts (Kadiyala et al., 2010). Metabolism of carbohydrate along with pancreatic regulation is the main function of thyroid hormone, so thyroid abnormalities may influence the development or progression of DM. Hyperthyroidism promotes hyperglycemia by reducing the actions of insulin and hence, the dosage of insulin needed to control diabetes will be higher in the patients with hyperthyroidism. Conversely, diabetic patients with comorbidity of hypothyroidism may require lower insulin dosage (Zhu et al., 2019). If thyroid abnormalities are being treated precisely it will benefit the diabetic patients to adjust glycemic control, reduce cardiac risks, and progress the daily routine.

There is a pressing need for routine thyroid testing of diabetic patients, which is lacking in our medical practices so far. Despite the evidence that there is a high prevalence of TD among diabetic patients globally, there is limited information on the prevalence of TD in Pakistani diabetic patients. We, therefore, evaluated thyroid status of diabetic patients from the local population of Quetta, Pakistan. These new clinical and demographic parameters might be helpful in introducing relevant guidelines at both national and international level.

\section{MATERIALS AND METHODS}

This study was carried out in the Centre for Advanced Studies in Vaccinology and Biotechnology (CASVAB), University of Balochistan in collaboration with Shaikh Khalifa Bin Zayed Hospital, Quetta. The study period was from December 2018 to May 2019. Ethical approval was granted by the concerned authorities of the CASVAB and the University of Balochistan. Patients were informed about the scope of the research, and samples and data were collected anonymously.

Inclusive criteria include newly diagnosed and previously diagnosed cases without treatment and/or diagnosed cases receiving treatment. Subjects not willing for the study and those with chronic or acute illness were excluded from the research. The population was selected without any bias for gender, ethnicity, education, interval, severity or control of diabetes, and it comprised 224 subjects aged between $<15$ to 75 years. Two categories were decided for the diagnosed subjects: patients with T1DM, patients with T2DM. An initial questionnaire consisting of general and systematic examination was filled by the researcher them-self to gain general health characteristics of the subjects such as sex and family status of DM. These patients had fasting blood sugar (FBS) levels of $>125 \mathrm{mg} /$ $\mathrm{dl}$ and postprandial blood sugar (PPBS) levels of $>200 \mathrm{mg} /$ $\mathrm{dl}$ and were receiving oral hypoglycemic and combined drugs and/or insulin injections.

Thyroid profile was measured by the thyroid hormone measuring assay of a Finecare analyzer using test markers of thyroid profile. According to thyroid abnormalities, the results of the diabetic patients were divided into two classes: those containing the normal thyroid profile (result of all of three T3, T4, and TSH) and other classes containing various concentrations which were further categorized as follows: (i) subclinical hypothyroidism which had regular range of both T3 and T4 and increased concentration of TSH. (ii) clinical hypothyroidism which had reduced range of both T3 and T4 and increased concentration of TSH. (iii) subclinical hyperthyroidism which had regular range of both T3 and T4 and decreased concentration of TSH. (iv) clinical hyperthyroidism which had an increased range of both $\mathrm{T} 3$ and $\mathrm{T} 4$ and decreased concentration of TSH.

\section{RESULTS}

The ages of the diabetic patients ranged from $<15$ to 75 years with an average of 45 years. A total of 224 diabetic patients were studied. The demographic profile of T1DM and T2DM patients (gender, age, time duration of DM, class of treatment) are shown in Table I. According to the data obtained, $92(41.07 \%)$ of the diabetic patients were male and 132 (58.93\%) were female. Thirty-four (15.18\%) diabetic patients were in the age group of $<15$ years, 22 $(9.82 \%)$ were in the range 16 to 30 years, $80(35.71 \%)$ were in the range 31 to 45 years, $46(20.54 \%)$ were in the range 46 to 60 years, and $42(18.75)$ were in the range 61 to 75 years. Out of the 224 diabetic patients, 34 (15.18\%) were diagnosed with diabetes within 1 year, $128(57.14 \%)$ patients had a time span up to 5 years, $38(16.96 \%)$ had a time span of 6-10 years, and $24(10.71 \%)$ patients had a time span of more than 10 years. On further enquiries, $130(58.04 \%)$ diabetic patients were on oral hypoglycemic agents, $28(12.50 \%)$ were receiving insulin therapy, and 40 $(17.86 \%)$ were prescribed oral hypoglycemic drugs along 
with insulin therapy. Moreover, there were 26 (11.61\%) diabetic patients who were not receiving any kind of treatment despite being diabetic.

Table I. Demographic data of all the diabetes mellitus patients enrolled in the study.

\begin{tabular}{lll}
\hline Gender distribution & Frequency & Percentage \\
\hline Male & 92 & $41.07 \%$ \\
Female & 132 & $58.93 \%$ \\
Total & 224 & $100.00 \%$ \\
Age in years & & \\
$<15$ & 34 & $15.18 \%$ \\
$16-30$ & 22 & $9.82 \%$ \\
$31-45$ & 80 & $35.71 \%$ \\
$46-60$ & 46 & $20.54 \%$ \\
61-75 & 42 & $18.75 \%$ \\
Total & 224 & $100.00 \%$ \\
Time span of diabetes mellitus & & \\
Diagnosed in less than 1 year & 34 & $15.18 \%$ \\
Diagnosed in last 1-5 years & 128 & $57.14 \%$ \\
Diagnosed in last 6-10 years & 38 & $16.96 \%$ \\
Diagnosed in last >10 years & 24 & $10.71 \%$ \\
Total & 224 & $100.00 \%$ \\
Class of treatment & & \\
Oral hypoglycemic agent & 130 & $58.04 \%$ \\
Insulin & 28 & $12.50 \%$ \\
Insulin/Oral hypoglycemic agent & 40 & $17.86 \%$ \\
No treatment & 26 & $11.61 \%$ \\
Total & 224 & $100.00 \%$ \\
\hline
\end{tabular}

Furthermore, there were 10 males $(29.4 \%)$ and 24 females $(70.6 \%)$ of T1DM, and there were 82 males $(43.2 \%)$ and 108 females $(56.8 \%)$ of T2DM (Table II). When we looked into the thyroid status of patients with T1DM, 59\% of cases were euthyroid and $41 \%$ of cases had thyroid abnormalities. The prevalence of subclinical hypothryroidism, clinical hypothyroidism and clinical hyperthyroidism were $24 \%, 12 \%$, and $6 \%$, respectively (Fig. 1). In T2DM patients, 69\% were euthyroid and 31\% had thyroid abnormalities. The prevalence of subclinical hypothryroidism, clinical hypothyroidism and clinical hyperthyroidism were $24 \%, 3 \%$, and $3 \%$, respectively (Fig. 1). Different thyroid function abnormalities are shown in Table III. The most prevalent cases detected among the diabetic patients were subclinical hypothyroidism displayed by $22(9.82 \%)$ males and 32 (14.28\%) females, followed by clinical hypothyroidism in $2(0.89 \%)$ males and $8(3.58 \%)$ females, and then clinical hyperthyroidism in $8(3.58 \%)$ females only. In our study, none of the subjects had subclinical hyperthyroidism.

Table II. Classification of diabetes as per gender.

\begin{tabular}{llll}
\hline & Gender & Frequency & Percentage \\
\hline Type 1 diabetic & Male & 10 & $29.4 \%$ \\
mellitus & Female & 24 & $70.6 \%$ \\
& Total & 34 & $100.0 \%$ \\
Type 2 diabetic & Male & 82 & $43.2 \%$ \\
mellitus & Female & 108 & $56.8 \%$ \\
& Total & 190 & $100.0 \%$ \\
\hline
\end{tabular}

Table III. Thyroid function abnormalities in percentage among the diabetic patients.

\begin{tabular}{lllll}
\hline $\begin{array}{l}\text { Thyroid func- } \\
\text { tion } \\
\text { abnormality }\end{array}$ & Gender Type 1 & $\begin{array}{l}\text { Type 2 } \\
\text { diabetes } \\
\text { mellitus }\end{array}$ & $\begin{array}{l}\text { Total } \\
\text { mellitus }\end{array}$ & \\
\hline Euthyroid & Male & $8(3.57 \%)$ & $60(26.78 \%)$ & $68(30.35 \%)$ \\
& Female & $12(5.37 \%)$ & $72(32.15 \%)$ & $84(37.52 \%)$ \\
Clinical hypo- & Male & $0(0.00 \%)$ & $2(0.89 \%)$ & $2(0.89 \%)$ \\
thyroidism & Female & $4(1.79 \%)$ & $4(1.79 \%)$ & $8(3.58 \%)$ \\
Subclinical hy- & Male & $2(0.89 \%)$ & $20(8.93 \%)$ & $22(9.82 \%)$ \\
pothyroidism & Female & $6(2.67 \%)$ & $26(11.62 \%)$ & $32(14.28 \%)$ \\
Clinical hyper- & Male & $0(0.00 \%)$ & $0(0.00 \%)$ & $0(0.00 \%)$ \\
thyroidism & Female & $2(0.89 \%)$ & $6(2.67 \%)$ & $8(3.56 \%)$ \\
Subclinical hy- & Male & $0(0.00 \%)$ & $0(0.00 \%)$ & $0(0.00 \%)$ \\
perthyroidism & Female & $0(0.00 \%)$ & $0(0.00 \%)$ & $0(0.00 \%)$ \\
Total & & 34 & 190 & 224 \\
& & $(15.17 \%)$ & $(84.83 \%)$ & $(100.00 \%)$ \\
\hline
\end{tabular}

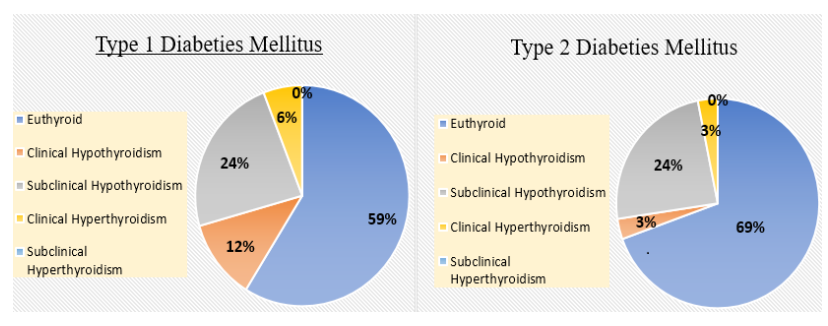

Fig. 1. Presentation of thyroid abnormalities in T1DM and T2DM patients.

\section{DISCUSSION}

It is well known that patients having autoimmune disorder are more prone to develop other autoimmune diseases. In body cells, both thyroid hormones and insulin 
work together and mutually affect metabolism of the body, any change in one of these can affect intermediatory metabolism and thus alter glucose homeostasis (Pramanik et al., 2018). Moreover, some studies have shown that diabetic patients have a higher risk of cardiovascular diseases (Preis et al., 2009), at the same time they have increased risk of thyroid disease compared to the general population (Kadiyala et al., 2010).

In the diagnosis of thyroid abnormalities, the levels of three different hormones known as T3, T4, and TSH were measured. In the current study, euthyroid (having normal levels of T3, T4, TSH) were $152(67.85 \%)$ out of a total of 224 diabetic patients. We found that $32 \%$ (72 out of 224) of the diabetic patients had thyroid abnormalities, out of which $67 \%$ were female. Unlike in cases of diabetes, which is prevalent in both genders, thyroid problems are more prevalent in females. Nearly one third of total diabetic patients in our study had thyroid abnormalities. At the same time, multiple studies have revealed an overall increased prevalence of TD among T2DM patients. A study by Radaiedeh and colleagues found the overall prevalence of $12.5 \%$ thyroid disease, with subclinical hypothyroidism $(5 \%)$ patients as the most common thyroid disease (Radaiedeh et al., 2004). Similarly, studies among Saudi and Greek type 2 diabetics showed 16\% (Akbar et al., 2006) and 12.3\% (Papazafiropoulou et al., 2010) prevalence of thyroid dysfunction, respectively. Interestingly, Udiong and co-workers found a high incidence $(46.5 \%)$ of abnormal thyroid hormone levels among the diabetics in Nigeria, with hypothyroidism $26.6 \%$, and hyperthyroidism, $19.9 \%$ (Udiong et al., 2007). Similar to our study, the prevalence of thyroid dysfunction was found higher in women than in men (Udiong et al., 2007; Papazafiropoulou et al., 2010; Iqbal et al., 2019).

The number of DM subjects showing thyroid abnormality in this current study was $72(32.15 \%)$ and $24.1 \%$ (54 patients) of these had subclinical hypothyroidism. Our study, therefore, showed that the most common thyroid abnormality found in the DM subjects was subclinical hypothyroidism. This is the similar to the observations made in other studies (Sugure et al., 1999; Chubb et al., 2005). A recent meta-analysis of 61 worldwide studies explained an adjusted pooled $10.2 \%$ prevalence of sub clinical hypothyroidism in T2DM patients (Han et al., 2015).

There are many reasons behind the disturbance of thyroid function in diabetic patients, one of these is alteration of TSH function by hypothalamic control, and in peripheral tissues hepatic conversion of T4 into T3. Another reason is consumption of different complex types of drugs in diabetes that increases the TSH level and decreases the levels of T3 and T4. A third reason is insulin injections, which inhibit the transformation of T4 to T3, as a result of which the level of T4 is raised. Autoimmune disorders and thyroid antibodies are a fourth reason for occurrence of thyroid abnormality in DM patients (Baron, 1955; Nishi, 2018; Pramanik et al., 2018; Carreras-Gonzalez and Perez, 2007). For the same reason, T1DM patients had more chance of developing thyroid abnormalities as compared to T2DM patients, and the same was found in the current study.

Our present study has several limitations. Firstly, the study used a relatively small sample size from a single institution of Quetta city, which may raise concerns about generalization of the data. Further studies with a larger sample selection are therefore required. Secondly, because of the nature of a cross-sectional study design, the causal relationship remains unknown, so in-depth longitudinal studies are required.

\section{CONCLUSIONS}

TD and DM are the two most common endocrine related disorders that are encountered in clinical practice. Control of the diabetes is a difficult task if there is coexistence of thyroid abnormality. We, therefore, evaluated thyroid status in diabetic patients from the local population of Quetta Pakistan. According to our data diabetics are more prone to develop thyroid abnormalities, out of which subclinical hypothyroidism was the most prevalent thyroid abnormality. Diabetic females were more susceptible than diabetic males. Moreover, T1DM patients had more chances of developing thyroid abnormalities as compared to T2DM patients. Regular screening of thyroid profile is recommended in routine medical practices for timely diagnosis of thyroid abnormalities in diabetics to lessen the risk of developing other associated morbidities.

\section{ACKNOWLEDGEMENTS}

Authors are grateful to Prof Dr. Shakeel Babar from CASVAB, University of Balochistan for his guidance and support of the study. Authors are very thankful to Dr. Muhammad Ibrahim (Head of Department) of Shaikh Khalifa Bin Zayed Hospital Quetta and Mr. Hafeezullah (lab attendant) for help and guidance in sample collection.

\section{Statement of conflict of interest}

Authors have declared that there is no conflict of interest.

\section{REFERENCES}

Aggarwal, N. and Razvi, S., 2013. Thyroid and aging or the aging thyroid? An evidence-based analysis of the literature. J. Thyroid Res., 2013 (Article ID 
481287): 1-8. https://doi.org/10.1155/2013/481287

Akbar, D.H., Ahmed, M.M. and Al-Mughales, J., 2006.

Thyroid dysfunction and thyroid autoimmunity in Saudi type 2 diabetics. Acta Diabetol., 43: 14-18. https://doi.org/10.1007/s00592-006-0204-8

Baron, D.N., 1955. Hypothyroidism and diabetes mellitus. The Lancet. 386: 796-800. https://doi. org/10.1016/S0140-6736(55)92387-4

Basit, A., Fawwad, A., Qureshi, H. and Shera, S.H., 2018. Prevalence of diabetes, pre-diabetes and associated risk factors: Second National Diabetes Survey of Pakistan (NDSP), 2016-2017. Br. med. J. Open. 8: e020961. https://doi.org/10.1136/ bmjopen-2017-020961

Carreras-Gonzalez, G. and Perez, A., 2007. Thyroid autoimmunity at onset of type 1 diabetes as a predictor of thyroid dysfunction. Diabetes Care, 30: e121. https://doi.org/10.2337/dc07-1504

Chubb, S.A., Davis, W.A. and Inman, Z., 2005. Prevalence and progression of subclinical hypothyroidism in women with type 2 diabetes: The Fremantle diabetes study. Clin. Endocrinol., 62: 480-486. https://doi.org/10.1111/j.13652265.2005.02246.x

Coller, F.A., and Huggins, C.B., 1927. Effect of hyperthyroidism upon diabetes mellitus: striking improvement in diabetes mellitus from thyroidectomy. Annls Surg., 86: 877-884. https:// doi.org/10.1097/00000658-192712000-00009

Galag, S.C., Rajalashmi, R., Srinath, K.M., and Madhu, B., 2016. Sub-clinical hypothyroidism in type 2 diabetes mellitus patients in a tertiary care hospital, Mysore. Indian J. Physiol. Pharmacol., 60: 255259.

Guillermo, E.U., Kashif, A.L., Mary, B.M., Helen, C.L., Frankie, S., Andrew, B., et al., 2003. Thyroid dysfunction in patients with type 1 diabetes. Diabetes Care, 26: 1181-1185. https://doi. org/10.2337/diacare.26.4.1181

Han, C., He, X., Xia, X., Li, Y., Shi, X., Shan, Z., and Teng, W., 2015. Subclinical hypothyroidism and type 2 diabetes: A systematic review and metaanalysis. PLoS One, 10: e0135233. https://doi. org/10.1371/journal.pone.0135233

Iqbal, M.A., Roohi, N. and Qureshy, A., 2019. Clinical trends of hepatic and renal profile in hyperthyroid subjects of Lahore, Pakistan. Punjab Univ. J. Zool., 34: 01-07. http://dx.doi.org/10.17582/journal. pujz/2019.34.1.1.7

Kadiyala, R., Peter, R., and Okosieme, O.E., 2010. Thyroid dysfunction in patients with diabetes: Clinical implications and screening strategies.
Int. J. clin. Pract., 64: 1130-1139. https://doi. org/10.1111/j.1742-1241.2010.02376.x

Khurana, A., Dhoat, P. and Jain, G., 2016. Prevalence of thyroid disorders in patients of type 2 diabetes mellitus. J. Indian Acad. Clin. Med., 17: 1215.

Nandyala, V., Gandiah. P., Sivarajappa. P., Indira, G. and Annavaram, N.R., 2013. Thyroid disorders in type 2 diabetes mellitus. Int. J. Rec. Trends Sci. Technol., 9: 250-255.

Nishi, M., 2018. Diabetes mellitus and thyroid diseases. Diabetol Int., 9: 108-112. https://doi.org/10.1007/ s13340-018-0352-4

Papazafiropoulou, A., Sotiropoulos, A., Kokolaki, A., Kardara, M., Stamataki, P. and Pappas, S., 2010. Prevalence of thyroid dysfunction among greek type 2 diabetic patients attending an outpatient clinic. J. clin. med. Res., 2: 75-78. https://doi. org/10.4021/jocmr2010.03.281w

Pramanik, S., Ghosh, S., Mukhopadhyay, P., Bhattacharjee, R., Mukherjee, B., Mondal, S.A., Ghosh, I., Bari, R. and Chowdhury, S., 2018. Thyroid status in patients with type 2 diabetes attending a tertiary care hospital in Eastern India. Indian J. Endocrinol. Metab., 22: 112-115. https:// doi.org/10.4103/ijem.IJEM_572_17

Preis, S.R., Pencina, M.J., Hwang, S.J., D’Agostino, R.B. Sr, Savage, P.J., Levy, D., Levy, D. and Fox, C.S., 2009. Trends in cardiovascular disease risk factors in individuals with and without diabetes mellitus in the Framingham Heart Study. Circulation, 120: 212-220. https://doi.org/10.1161/ CIRCULATIONAHA.108.846519

Radaiedeh, A.R., Nusier, M.K., Amari, F.L., Bateiha, A.E., El-Khateeb, M.S. and Naser, A.S., 2004. Thyroid dysfunction in patients with type 2 diabetes mellitus in Jordan. Saudi med. J. 25: 1046-1050.

Sarwar, N., Gao, P., Seshasai, S.R., Gobin, R., Kaptoge, S., Ingelsson, E., Lawlor, D.A., Selvin, E., Stampfer, M., Stehouwer, C.D.A., Lewington, S., Pennells, L., Thompson, A., Sattar, N., White, I.R., Ray, K.K. and Danesh, J. 2010. Diabetes mellitus, fasting blood glucose concentration, and risk of vascular disease: A collaborative meta-analysis of 102 prospective studies. The Lancet, 375: 2215-2222. https://doi.org/10.1016/S0140-6736(10)60484-9

Sugure, D.D., Mc Evoy, M. and Drury, M.I., 1999. Thyroid disease in diabetics. Postgrad. med J., 58: 680-684. https://doi.org/10.1136/pgmj.58.685.680

Udiong, C.E.J., Udoh, A.E. and Etukudoh, M.E., 2007. Evaluation of thyroid function in diabetes mellitus in Calabar, Nigeria. Indian J. clin. Biochem., 22: 
74-78. https://doi.org/10.1007/BF02913318

Vanderpump, M.P., 2011. The epidemiology of thyroid disease. Br. med Bull., 99: 39-51. https://doi. org/10.1093/bmb/ldr030

Wang, C., 2013. The relationship between type 2 diabetes mellitus and related thyroid diseases. J. Diabet. Res., 390534: 1-9. https://doi.org/10.1155/2013/390534

Wild, S., Roglic, G., Green, A., Sicree, R. and King, H., 2004. Global prevalence of diabetes. Estimates for the year 2000 and projections for 2030. Diabet. Care, 27: 1047-1053. https://doi.org/10.2337/ diacare.27.5.1047

Zhu, Y., Xu, F., Shen, J., Liu, Y., Bi, C., Liy, J., Li, Y.,
Wang, X., Gao, Z., Liang, L., Chen, Y., Sun, W., Guan, Q., Zhang, J., Luo, Z., Guo, L., Cai, X., Li, L., Xiu, L., Yan, L., Li, C., Shi, X., Zhu, M., Kuang, J., Li, G. and Ji, L., 2019. Prevalence of thyroid dysfunction in older Chinese patients with type 2 diabetes. A multicenter cross-sectional observational study across China. PLoS One, 14: e0216151. https://doi.org/10.1371/journal. pone. 0216151

Zimmat, P., Albert, K.G. and Shaw, J., 2001. Global and societal implications of the diabetes epidemic. Nature, 414: 782-787. https://doi. org/10.1038/414782a 